\title{
A institucionalização da Memória e da História do setor elétrico paulista
}

DOSSIER ELETROMEMÓRIA: PAISAGEM E HisTóRIA

\section{Renato de Oliveira Diniz}

Historiador, Doutor em História da Ciência [USP]. Curador do Projeto CPFL 100 Anos (2011-2013).

Desenvolve atividades na área de memória empresarial e de curadoria de projetos culturais. São Paulo [SP]

Brasil.<rdiniz@uol.com.br>.

\section{Resumo}

A história do setor elétrico não pode só responder a questões teóricas típicas dos historiadores que a pesquisam e produziram os trabalhos que já constituem um corpo significativo de conhecimento científico. 0 trabalho de preservação e divulgação da memória dos empreendimentos ligados à produção e uso da energia elétrica pode e deve também responder a questões de gestão desses empreendimentos como negócios e como concessão de serviço público. As diversas iniciativas de institucionalização da memória e da história do setor elétrico paulista, a partir dos anos 1980, são reflexos da conjuntura institucional do setor.

\section{Palavras-chave}

Setor elétrico, institucionalização da memória, memória empresarial, preservação de acervo, divulgação de acervo.

\section{The institutionalization of Memory and History of Sao Paulo Power Industry}

\begin{abstract}
The history of the electrical utility sector should respond not only to typical theoretical questions of the historians that have researched and produced works that are already a significant body of scientific knowledge. The preservation and the divulgation of the memory of the enterprises involved in the production and use of electric power can and must respond to management issues of those enterprises both as business matters and as public service concessions. The various institutionalized initiatives on behalf of the memory and history of São Paulo electrical sector from the 1980's on reflect their institutional context.
\end{abstract}

\section{Keywords}

Electricity sector; memory institutionalization; corporate memory; preservation of records; record divulgation. 


\section{Introdução}

[...] o que é mais importante no contexto atual é que todos os grupos numa sociedade, por mais coesos que sejam (e o historiador muitas vezes tem razão em tratá-los como tal), geram um certo número de extravagantes ou dissidentes. Isto está particularmente sujeito a acontecer entre os intelectuais. Não me refiro aos argumentos comuns entre os intelectuais, guiados pelo princípio fundamental de uma aceitação comum dos princípios pressupostos da sociedade, mas de desafios a estes pressupostos. Nas sociedades democráticas ocidentais, tais desafios, desde que confinados a um punhado de dissidentes, são tolerados, e aqueles que os apresentam podem encontrar leitores e uma audiência (CARR, 2002) ${ }^{1}$.

Como uma das atividades do projeto "Eletromemória 1" apresentamos, em setembro de 2010, o trabalho "O papel dos setores público e privado na preservação da cultura material do setor elétrico" no III Seminário Internacional História \& Energia, organizado pelo professor Gildo Magalhães, com o apoio da Fundação Energia e Saneamento ${ }^{2}$. No texto da comunicação apresentada defendemos que o papel dos organismos públicos e da iniciativa privada em relação à preservação da cultura material do setor elétrico deve ser diretamente proporcional ao protagonismo desses setores (público e privado) e de sua respectiva responsabilidade cultural/histórica/social no processo de eletrificação; hoje acrescentamos que essa participação não só é proporcional ao protagonismo como é reflexo na forma como é institucionalizada e como se desenvolve - da visão da energia elétrica como serviço público e/ou como negócio. A essas observações podemos também acrescentar o conceito de responsabilidade histórica tal qual defendido pelo professor Paulo Nassar quando relaciona a atuação das empresas nas comunidades onde atuam com sua participação na construção da cultura e da história dessas comunidades. Ao reconhecer essa relação e preservar e divulgar os registros das suas memórias, as empresas exercem sua responsabilidade histórica, pois direta e indiretamente estão preservando parte da história e da memória das comunidades onde vendem seus produtos e serviços. Neste texto apresentamos uma primeira tentativa de sistematizar as diversas iniciativas de se preservar e divulgar a memória e a história do setor elétrico paulista em instituições diretamente vinculadas a esse estratégico setor econômico, uma das bases, em todos os sentidos, de nossa sociedade como ela se configura hoje. Como primeira tentativa de sistematização, está apoiado mais na experiência profissional do autor do que em extensiva pesquisa e visa propor um roteiro da história da historiografia ou da institucionalização da história do setor elétrico em São Paulo. É importante destacar que entendemos, para efeito desta apresentação, produção historiográfica em seu sentido mais amplo, ou seja, toda e qualquer produção que tenha por tema a história da energia elétrica em São Paulo: livros, teses, periódicos, "folders", documentários, exposições, museus. Nosso foco são as formas de institucionalização da memória da indústria de produção e venda de eletricidade como um dos aspectos de gestão dos negócios, como no caso da Light canadense desde sua instalação no Brasil, ou como forma de definição de identidade, como no caso das empresas estatais controladas pelo governo do estado até 1997.

Beth Totini e Élida Gagete indicam que os primeiros trabalhos sobre memória empresarial foram publicados ainda nos anos 1960 como iniciativa de "acadêmicos, interessados na reflexão sobre a estrutura e a evolução industrial brasileira" ${ }^{3}$. Esses trabalhos, sob nosso ponto de vista, estavam inseridos no quadro de entendimento da formação do capitalismo e da industrialização no país e tinham a clara visão de que, ao entendermos nossa história econômica, poderíamos dar o salto para o desenvolvimento. Em meados dos anos 1970 numa tentativa quase quixotesca foi criada a Fundação Museu da Tecnologia de São Paulo que, mesmo hoje sem solução de continuidade, em

\footnotetext{
${ }^{1}$ Edward Hellet Carr. $O$ que é história? Rio de Janeiro: Paz e Terra, 2002, p.14.

${ }^{2}$ Gildo Magalhães (org.). História e Energia: Memória, Informação e Sociedade. São Paulo: Alameda, 2012, p.333-338.

${ }^{3}$ Beth Totini e Élida Gagete no em "Memória Empresarial, uma análise da sua evolução", artigo publicado no volume organizado por Paulo Nassar: Memória de Empresa: história e comunicação de mãos dadass a construir o futuro das organizações, publicado pela Associação Brasileira de Comunicação Empresarial - ABERJE, em 2004.
} 
1987 abrigou a Expo CESP, uma das primeiras iniciativas de sistematizar e apresentar ao grande público a história da energia elétrica em São Paulo.

O processo de estatização do setor elétrico em São Paulo foi iniciado em meados dos anos 1950 com a criação das empresas antecessoras da CESP e encarregadas de construir e operar as novas usinas hidrelétricas do estado. Em 1975 o governo paulista por meio da CESP adquiriu do governo federal o controle acionário da CPFL. Podemos dizer que o processo de estatização foi finalizado em 1981 com a transferência do sistema paulista da Light, renomeado Eletropaulo, para o governo do estado. Observamos então que, apesar da implementação do projeto de transferência das atividades do setor elétrico para as mãos do estado ter sido defendido até 1964 por tendências mais liberais da política brasileira e também de ser a estatização de modo geral defendida pelos grupos mais à esquerda, o controle estatal desse setor foi complementado pelos governos militares entre os anos 1960 e início dos 1980.

Em 1983, estávamos caminhando para a redemocratização do país e, após a posse do primeiro governador de São Paulo eleito diretamente, foi criado na Eletropaulo o Departamento de Patrimônio Histórico - DPH. Nesse mesmo período são criados o Projeto Memória CESP e os diversos "centros de memória" descentralizados na CPFL. Na Comgás, empresa de distribuição de gás canalizado, também estadualizada e dentro do mesmo quadro de "recuperação da memória" das empresas de energia de São Paulo, foram iniciados projetos de organização e divulgação dos registros históricos. Associamos estas primeiras iniciativas, bem sucedidas sem dúvida, ao processo de redemocratização quando o projeto de estatização estava completo e as empresas de energia, agora controladas por um estado democrático passaram, dentro da visão do momento, a ser administradas do ponto de vista social e não mais dos interesses de grupos internacionais desligados desse ponto de vista, como poderia ser o caso do "polvo canadense", a poderosa Light! Recuperar e divulgar a memória do setor, além de simples tarefa técnica, tornou-se parte do movimento de reconhecimento e de reafirmação da identidade nacional sufocada nos "anos de chumbo". Conhecer a história das "nossas empresas de energia", assim como outras facetas da história de nosso desenvolvimento econômico, caminhou na direção da retomada da cidadania perdida no período anterior. A criação em 1986 pela Eletrobrás do Centro da Memória da Eletricidade do Brasil - Memória da Eletricidade - no Rio de Janeiro, foi um passo importante para a preservação dos registros do setor elétrico em todo o país, assim como por meio de uma extensa produção bibliográfica de referência para a história da energia elétrica no Brasil, e serviu de excelente contraponto às iniciativas dos setores de memória das estatais paulistas. Ao lançar, em 1988, o "Panorama da História da Energia Elétrica no Brasil” a Memória da Eletricidade criou o primeiro "manual" para esse tema em nossa historiografia, ao sistematizar de maneira bastante abrangente o conhecimento do processo de eletrificação de todas as regiões do Brasil até aquele momento.

Voltando a São Paulo podemos afirmar que o DPH, Departamento de Patrimônio Histórico da Eletropaulo - Eletricidade de São Paulo S.A. foi, de 1983 a 1998, quando seu acervo e grande parte de sua equipe técnica foram incorporados pela Fundação Patrimônio Histórico da Energia de São Paulo, a experiência de institucionalização mais organicamente estruturada do período estatal. O Departamento estava inserido no organograma corporativo da Eletropaulo como um departamento da Superintendência de Comunicação, vinculada à presidência da empresa. Com orçamento anual próprio para desenvolver seus projetos, sua equipe técnica era composta por profissionais especializados contratados em regime da CLT e com carreira funcional inserida na política de recursos humanos da corporação. Nesse contexto o acervo da antiga Light em São Paulo foi tecnicamente tratado, organizado e divulgado em periódicos, publicações especiais, exposições e seminários". Destacamos, além da série de publicações o "I Seminário História \& Energia", realizado em 1986, e a grande exposição "A Cidade Iluminada", realizada em 1989 e que retratou a substituição da iluminação pública a gás pela iluminação elétrica nas ruas da cidade de São Paulo nas primeiras décadas do século XX. As publicações e exposições do DPH da Eletropaulo exploraram o acervo, especialmente o conjunto de fotografias, que além de explicitarem o modus operandi de uma empresa internacional na conquista e manutenção do monopólio de seus negócios,

\footnotetext{
${ }^{4}$ Boletim Histórico, Cadernos História \& Energia, Revista Memória e Memória Eletropaulo, A História da Light, São Paulo Registros, Exposição Cidade Iluminada, Seminário História \& Energia.
} 
são um dos melhores conjuntos de registros iconográficos da cidade de São Paulo do final do século XIX a meados do XX. Relatórios técnicos, relatórios anuais, coleção de recortes de jornais, documentos da administração revelaram, além do modo como a Light atuava junto ao poder e à opinião pública, por exemplo, que a empresa tinha uma clara política de registro e preservação de sua memória técnica e de expansão, e a memória administrativa como um aspecto importante na condução de seus negócios.

É também dos primeiros anos da década de 1980 o Projeto Memória CESP, desenvolvido inicialmente por meio de um convênio com o Instituto de Estudos Brasileiros da Universidade de São Paulo. Apesar de, em seus primeiros anos, ser um projeto contratado inicialmente pela Diretoria de Comunicação e depois pela Diretoria Administrativa da Companhia Energética de São Paulo e de contar apenas com pesquisadores advindos da universidade (professores e alunos de pós-graduação), não sendo portanto um setor inserido na estrutura da empresa, o Projeto Memória teve uma produção significativa. Realizou em 1985 o Seminário "CESP conta sua história" e produziu, em 1986, o primeiro número da série Fascículos da História da Energia em São Paulo: "SACERC - S.A. Central Elétrica Rio Claro", como resultado da organização preliminar do acervo da empresa e do grupo de origem privada originado em 1895 com a usina hidrelétrica de Corumbataí em Rio Claro. 0 grupo SACERC e Associadas foi estatizado em 1965 e, em 1966, incorporado na CESP no momento de sua criação. Em 1987 o Projeto Memória abriu à visitação pública a já citada exposição "História da Energia - CESP" nas instalações do Museu da Tecnologia de São Paulo. No final dos anos 1980 as atividades do Projeto Memória são transferidas para funcionários da empresa, porém sem uma estrutura própria e alocados na biblioteca ou na comunicação. Mesmo assim publicaram "Falam os Pioneiros da Energia" (1987), a "Bibliografia da História da Energia Elétrica no Brasil" (1988), e cinco títulos dos "Fascículos" (1988 a 1995), entre outros títulos. Em março de 1998 o acervo histórico, a biblioteca da CESP e dois técnicos foram parcialmente incorporados pela Fundação Patrimônio Histórico da Energia de São Paulo.

A Companhia Paulista de Força e Luz - CPFL também iniciou nos anos 1980 um movimento de estudo de sua história. Lançou em 1982, quando comemorou sete décadas de sua fundação um dos livros "clássicos" da história da indústria da eletricidade em São Paulo. "Energia e Desenvolvimento - 70 Anos da Companhia Paulista de Força e Luz", que retrata a trajetória da empresa criada em 1912 por cafeicultores do interior do estado, as compras pelo grupo americano Amforp em 1927 e pela Eletrobrás em 1965, e a transferência em 1975 para o governo paulista. Durante o período estatal a empresa nunca chegou a ter uma área específica para tratar as questões de memória, mas publicou importantes registros de sua trajetória histórica como, em 1983, o livreto de comemoração dos cem anos da Usina de Monjolinho em São Carlos, considerada a primeira usina hidrelétrica do estado. Em 1992, nova publicação comemorou os oitenta anos da empresa. A nosso ver, por não ter desenvolvido uma ação centralizada de preservação e tratamento de seu acervo histórico, a CPFL estatal (1965/1997) não nos legou um conjunto de registros de sua memória disponibilizados para consulta pública. Toda vez que uma importante data de comemoração demandava uma publicação, técnicos da empresa e pesquisadores contratados consultavam os documentos conhecidos e disponíveis para produção da publicação e do evento. Muitos desses documentos se encontram, até hoje, em boas condições sob a guarda da biblioteca da empresa. Em 1997, às vésperas da privatização, a CPFL dispunha de cinco núcleos descentralizados, ligados às regionais administrativas da empresa e em processo de avaliação ou de desativação: Araraquara, Bauru, Campinas, Ribeirão Preto e São José dos Campos.

Em 1996, no processo de desestatização das empresas energéticas paulistas e por sugestão de técnicos da área de memória dessas empresas (CESP, CPFL, Comgás e Eletropaulo) foi criado na Secretaria de Estado de Energia um primeiro grupo de trabalho para estudar a continuidade do trabalho de preservação dos registros históricos dessas empresas no novo cenário que estava sendo construído. Principalmente em função da característica básica do Programa Estadual de Desestatização, de descentralização dos negócios de geração, transmissão e distribuição das empresas de energia elétrica, criando novas empresas a partir da cisão da CESP e da Eletropaulo - a CPFL atuava quase que exclusivamente na área de distribuição - o grupo de trabalho propôs a constituição de uma fundação de direito privado que receberia o acervo das três empresas originais. Em janeiro de 1997, um segundo grupo de trabalho, agora com a missão de formatar a 
fundação, foi constituído, sendo a Fundação Patrimônio Histórico da Energia de São Paulo criada em março de 1998, tendo por missão a guarda, preservação e divulgação do acervo histórico da CESP, Comgás e Eletropaulo. A CPFL, após ser privatizada não aderiu à constituição da Fundação, não transferindo a guarda de seu acervo histórico para a nova instituição recém criada.

O espírito do projeto de criação da hoje Fundação Energia e Saneamento - FES foi o de adequar o trabalho de preservação da memória do setor energético em São Paulo ao novo contexto de empresas controladas pela iniciativa privada, e para tanto previu, além da participação no conselho curador de representantes das novas empresas resultantes do processo de privatização, a manutenção financeira desse trabalho por um período inicial de cinco anos. Após esse período a instituição deveria desenvolver junto a essas empresas novas formas de financiamento como a venda de serviços às próprias empresas então mantenedoras e a geração de energia nas quatro pequenas centrais hidrelétricas herdadas das empresas estatais formadoras. Nesses cinco primeiros anos foram realizadas as tarefas básicas de integração do acervo recebido (arquivo, biblioteca, objetos museológicos, patrimônio arquitetônico), projeto e inauguração de cinco núcleos museológicos, continuidade de publicação da Revista Memória Eletropaulo como Revista Memória Energia, dos cadernos História \& Energia, de livros especiais como o livro "Imagens de São Paulo - Gaensly no acervo da Light, 1899-1925", e a realização do II Seminário Internacional História \& Energia em 2002. Como já afirmamos em nossa tese de doutorado dois projetos nesse período, quando ocupamos o cargo de Superintendente/Diretor Técnico, nos demandaram bastante atenção: foram a implantação dos cinco primeiros núcleos do Museu da Energia e a repotenciação das quatro usinas recebidas no processo de criação. 0 projeto de museu descentralizado do Museu da Energia tem suas origens no Departamento de Patrimônio Histórico da Eletropaulo ${ }^{5}$. Apesar de estar no momento enfrentando dificuldades de financiamento de suas atividades, é um projeto idealizado "a partir do patrimônio do setor energético [...] e seu acervo era composto em sua essência por objetos representativos desse setor"6, o que garantiu, num primeiro momento, a relação orgânica de seu projeto com a história da energia em nosso estado, principalmente se também entendermos o projeto de um museu e a sua implantação como produção historiográfica. 0 projeto de repotenciação das quatro usinas da Fundação muito nos entusiasmou por três aspectos: por fornecer aporte financeiro às atividades do Museu da Energia a partir de seu próprio acervo; por retomar a produção de energia em uma usina histórica; e pela combinação dos dois aspectos anteriores, o que o transformou efetivamente num museu vivo ao oferecer ao visitante a experiência de observar o que ao se transformar numa instalação museológica recobrou sua capacidade real de produzir o insumo para o qual foi originariamente construída há um século atrás e, ao menos em parte, financiar a atividade de museu. Nos seus dezoito anos de existência, além de desenvolver e trazer a público projetos que se tornaram referência na história do setor - como: publicações; projetos de tratamento arquivístico e de assistência técnica na área de memória para empresas do setor e fora dele; exposições; convênios de cooperação com instituições culturais públicas e privadas; eventos de divulgação - a Fundação se tornou uma instituição central das ações de preservação da memória e da história do setor elétrico em São Paulo. Um bom exemplo de projeto de cooperação com instituição pública foi o Eletromemória 1, realizado de 2007 a 2010 e o III Seminário Nacional História \& Energia, realizado em 2010. Organizado como atividade de conclusão do Eletromemória, o III Seminário, além de apresentar uma sistematização dos avanços alcançados pelo projeto, nos dá uma medida do estado, naquele momento, do conhecimento produzido nas últimas décadas na área da história da energia no país, ao reunir parte significativa dos estudiosos do assunto. Os anais do seminário, publicados em 2012, registram esse conhecimento7.

A FES passa hoje por um momento de readequação institucional, fruto das dificuldades de financiamento que enfrentou nos últimos dez anos. Necessário se faz que os protagonistas da história da indústria de energia elétrica, do gás e do saneamento público, tal como acima definimos,

\footnotetext{
${ }^{5}$ Rosane Tróia, Renato Diniz, Tânia Ferreira. Museu Descentralizado. Revista Memória, São Paulo: Eletropaulo/ Departamento de Patrimônio Histórico, no 9, out/nov/dez 1990, pp. 51/56.

${ }^{6}$ Mirian Yagui na dissertação de mestrado "Museus e patrimônio industrial: um estudo sobre a musealização do setor elétrico no estado de São Paulo", defendida em 2014 no Programa de Pós-Graduação Interunidades em Museologia do Museu de Arqueologia e Etnologia da Universidade de São Paulo.
}

${ }^{7}$ Gildo Magalhães (org.). História e Energia: memória, informação e sociedade. São Paulo, Alameda, 2012. 
conscientes de sua responsabilidade frente à sua própria história e à história dessas importantes concessões públicas, participem ativamente do processo de recriação da FES.

Neste inventário quase pessoal das instituições que preservam a memória da energia elétrica em São Paulo, acreditamos ser também necessário destacar a criação, em 2004, do Centro de Documentação e Memória Camargo Corrêa - CDMCC, cujo acervo contém, além do grande número de registros de outras obras públicas e privadas que a construtora do Grupo Camargo Corrêa executou, um conjunto significativo de fotografias e de imagens e produções em vídeo e película das grandes usinas construídas a partir do final dos anos 1950 pelas empresas estatais paulistas. Como exemplo podemos citar Jupiá, Ilha Solteira e Água Vermelha. Fechado à consulta desde o início de 2012, encontra-se atualmente em processo de reavaliação para possível reabertura. Outro projeto do qual participamos como curador e que, apesar de não representar uma iniciativa de institucionalização da memória empresarial de um dos maiores grupos concessionários de serviços de energia elétrica do país, dada a sua amplitude, produziu uma historiografia ${ }^{8}$ importante para nossa área de pesquisa: o projeto CPFL 100 Anos. Criado para comemorar os cem anos de fundação da Companhia Paulista de Força e Luz, empresa matriz do atual grupo CPFL, promoveu um início do tratamento técnico do conjunto arquivístico e museológico por uma equipe da FES. Dentro do projeto maior, o Projeto Memória Viva recolheu e publicou em site da internet, ainda hoje disponível, o depoimento de 100 profissionais que direta ou indiretamente participaram da história da empresa. No mesmo site é possível ter uma visão dos fatos históricos de destaque da CPFL e conhecer o estado do tratamento técnico de seu acervo histórico ${ }^{9}$. Com o que deveria ser o primeiro núcleo de um museu descentralizado foi instalado em sua sede o "Hall da Energia", exposição que retrata a história da empresa com equipamentos de alta tecnologia.

A realização de pesquisas acadêmicas produziu, nas últimas três décadas, um pequeno volume de dissertações de mestrado e teses de doutorado. No levantamento que fizemos em 2010 focado nesse tipo de produção, nesse período e no estado de São Paulo que, de 1980 a 2010, não foram produzidas mais do que três dezenas de trabalhos, sendo que os mais recentes tratavam de questões referentes ao período pós-privatização e tinham uma visão mais de análise econômica do que de perspectiva histórica. Dentre essa produção destacamos: de Márcio Wohlers de Almeida, Estado e Energia Elétrica em São Paulo, tese de doutorado defendida na UNICAMP, em 1980; de Ricardo Maranhão, Capital Estrangeiro e Estado na Eletrificação Brasileira: a Light, 1947-1957, tese defendida na USP, em 1993; de Cláudio Schuller Maciel, Globalização, Crise do Padrão de Financiamento da Economia e Reestruturação Institucional do Setor Elétrico Brasileiro, tese defendida na UNICAMP, em 1996; de Alexandre Macchione Saes, Conflitos do Capital: Light versus CBEE na formação do capitalismo brasileiro, tese defendida na UNICAMP, em 2008; de Moises Ari Zilber, Planejamento Estratégico em Estatais de Energia Elétrica: o caso das empresas do estado de São Paulo, tese defendida na USP, em 1989. Dos trabalhos mais recentes destacamos duas dissertações de mestrado defendidas na Universidade de São Paulo: de Alexandre Ricardi, A Companhia Água e Luz do Estado de São Paulo e suas relações de conflito na formação do parque elétrico paulistano, 1890-1910, de 2013 e, de Miriam Midori Peres Yagui, Museus e Patrimônio Industrial: um estudo sobre a musealização do setor elétrico no estado de São Paulo, de 2014; e duas teses de doutorado: de Renato Diniz, A Intervenção Estatal no Setor Elétrico Paulista: As grandes empresas e as grandes usinas -1953/1997, defendida na USP em 2011; e de Debora Mortati, $A$ implantação da Hidreletricidade e o processo de ocupação do território no interior paulista (1890-1930), defendida na UNICAMP em 2013.

\footnotetext{
${ }^{8}$ No sentido amplo que defendemos. Dois livros: Ricardo Maranhão e Simone Biehler Mateos. Cem Anos de História e Energia. São Paulo: Andreato, 2012; Renato Diniz. Cem Anos de História e Energia. São Paulo: Via das Artes, 2012. A exposição itinerante Cem Anos de História e Energia nas cidades de Campinas, Santos e Sorocaba. Um filme documentário: Cem Anos Luz, de Sérgio Roizenbit. Um show de MPB e o respectivo DVD: Cem Anos de Luz e Som, com direção de Zuza Homem de Mello e Gringo Cardia. A exposição permanente do Hall da Energia e o Projeto Memória Viva acima citados, além do Circuito Energia, uma série de eventos esportivos de corrida em alusão aos cem anos da empresa.

${ }^{9}$ http://www.cpfl.com.br
}

DINIZ, R.O. A institucionalização da Memória e da História do setor elétrico paulista. Labor \& Engenho,

Campinas [SP] Brasil, v.9, n.1, p.93-103, jan./mar. 2015. Disponível em: www.conpadre.org 
Em 2014, a Funcesp iniciou um promissor processo ao comemorar seus 45 anos de criação. Constituída em 1969 como Fundação de Assistência aos Empregados da CESP - FAEC, dez anos depois passou a denominar-se Fundação CESP, com o objetivo de fornecer assistência de saúde e plano previdenciário aos profissionais da CESP. Posteriormente passou a fornecer esses e outros benefícios trabalhistas aos empregados da CPFL e Eletropaulo. Criada no contexto das empresas estatais de energia, a história inicial da Funcesp revela um aspecto importante da política de estado de recursos humanos para a massa de trabalhadores lotada nessas empresas. Após a privatização, com a readequação ao novo contexto, continuou sendo uma testemunha de parte da história do setor elétrico no estado de São Paulo. A publicação do livro "Funcesp: 45 anos para o futuro, 1969-2014"10 deu início ao recolhimento e reunião de registros que constituíram o futuro acervo da instituição, com a finalidade de também disponibiliza-lo à consulta.

A história de um setor econômico básico como o setor elétrico, especialmente hoje, após o processo de privatização do final do século passado não pode só responder a questões teóricas típicas dos historiadores que a pesquisam e produziram os trabalhos que já constituem um corpo significativo de conhecimento científico. 0 trabalho de preservação e divulgação da memória dos empreendimentos ligados à produção e uso da energia elétrica pode e deve também responder a questões de gestão desses empreendimentos como negócios e como concessão de serviço público. Nessa direção a utilização das leis de incentivo fiscal não pode ser a principal fonte de financiamento de projetos e instituições, pois os recursos tendem a ser aplicados em projetos pontuais, muitas vezes de forte sentido comemorativo e que não asseguram a continuidade e o fortalecimento institucional, a ponto de não se criar uma produção firme e perene. As experiências do Departamento de Patrimônio Histórico da Eletropaulo e da Fundação Energia e Saneamento nos mostram que é necessária, em condições ideais, a existência de uma instituição estruturada, com objetivos definidos, orçamento e equipe bem remunerada e que não estejam simplesmente ligados a estratégias pontuais das empresas, públicas ou privadas. Por isso mesmo podemos dizer que é grande o potencial de desenvolvimento da história da energia elétrica ao considerarmos as inúmeras possibilidades que podem ser abertas com a cooperação entre universidade, empresas e administração pública. 0 projeto Eletromemória, ao apresentar às empresas essas possibilidades, demonstra claramente esse potencial. Aos jovens pesquisadores, especialmente aos que participam do Eletromemória 2, cabe, a partir de seu desenvolvimento profissional e de sua produção, criar as novas possibilidades.

\section{Ilustrações}

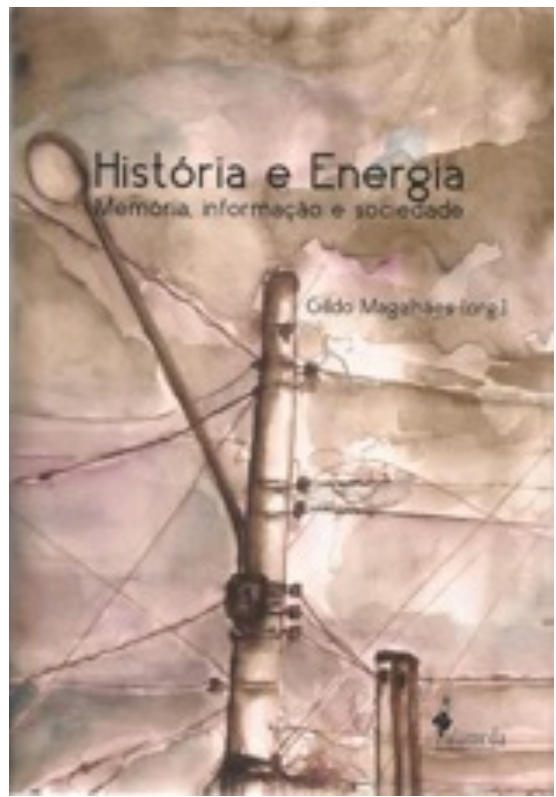

Figura 1. Anais do III Seminário

Internacional História e Energia, 2012.

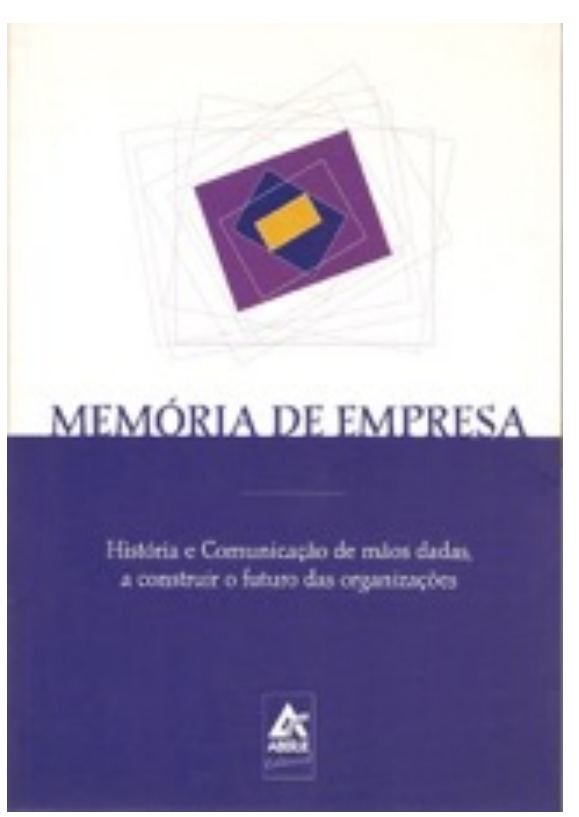

Figura 2. Memória de Empresa, 2004.

\footnotetext{
${ }^{10}$ Renato Diniz, São Paulo: Perfil Cultural, 2014.
} 


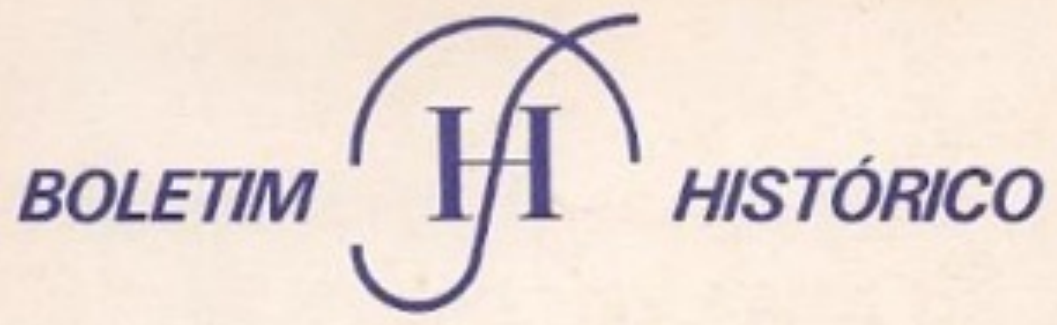

\section{ELETRICIOADE DE \\ SAO PALLO S.A.}

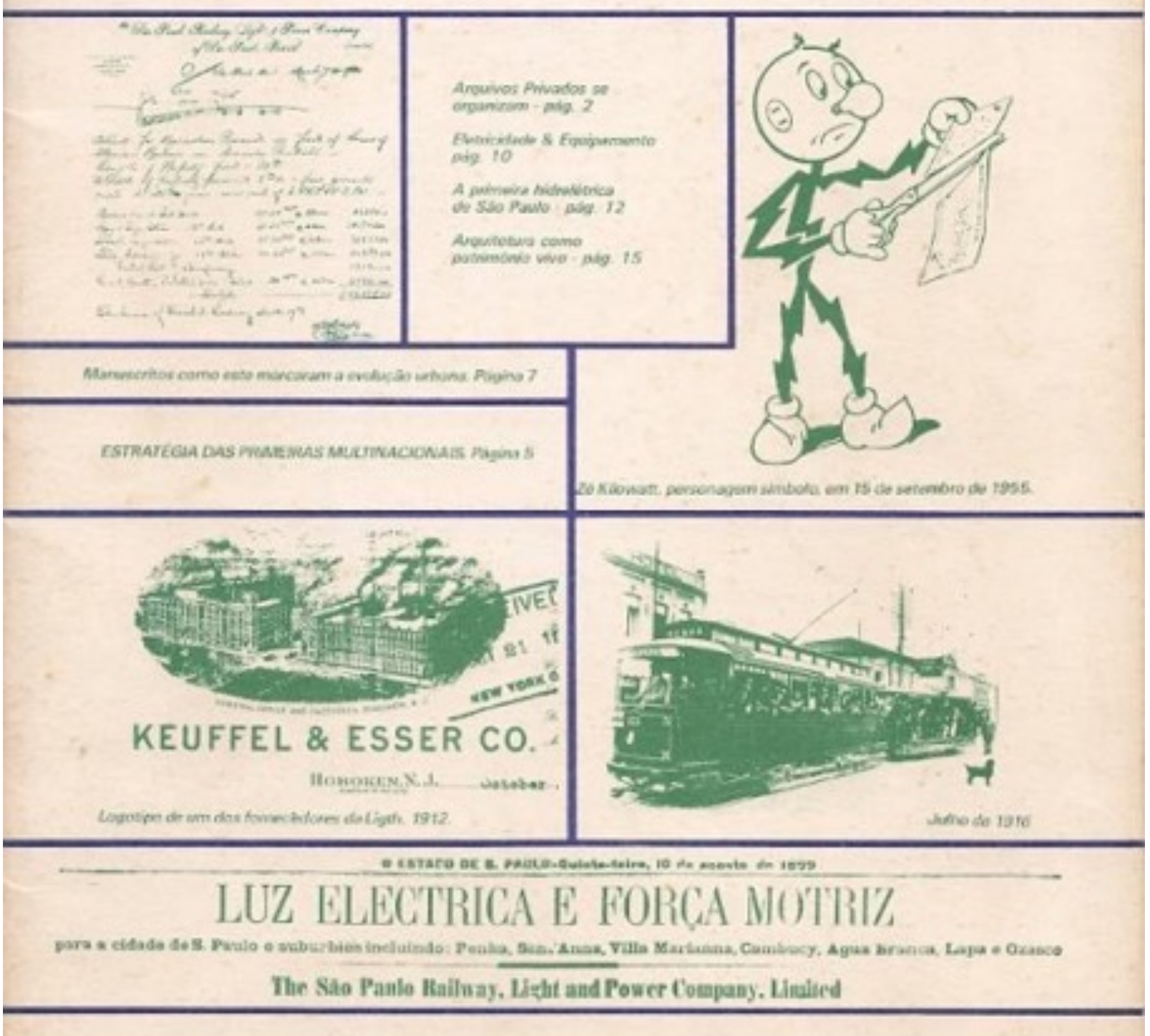

Figura 3. Boletim Histórico noㅜ 1, 1985. 


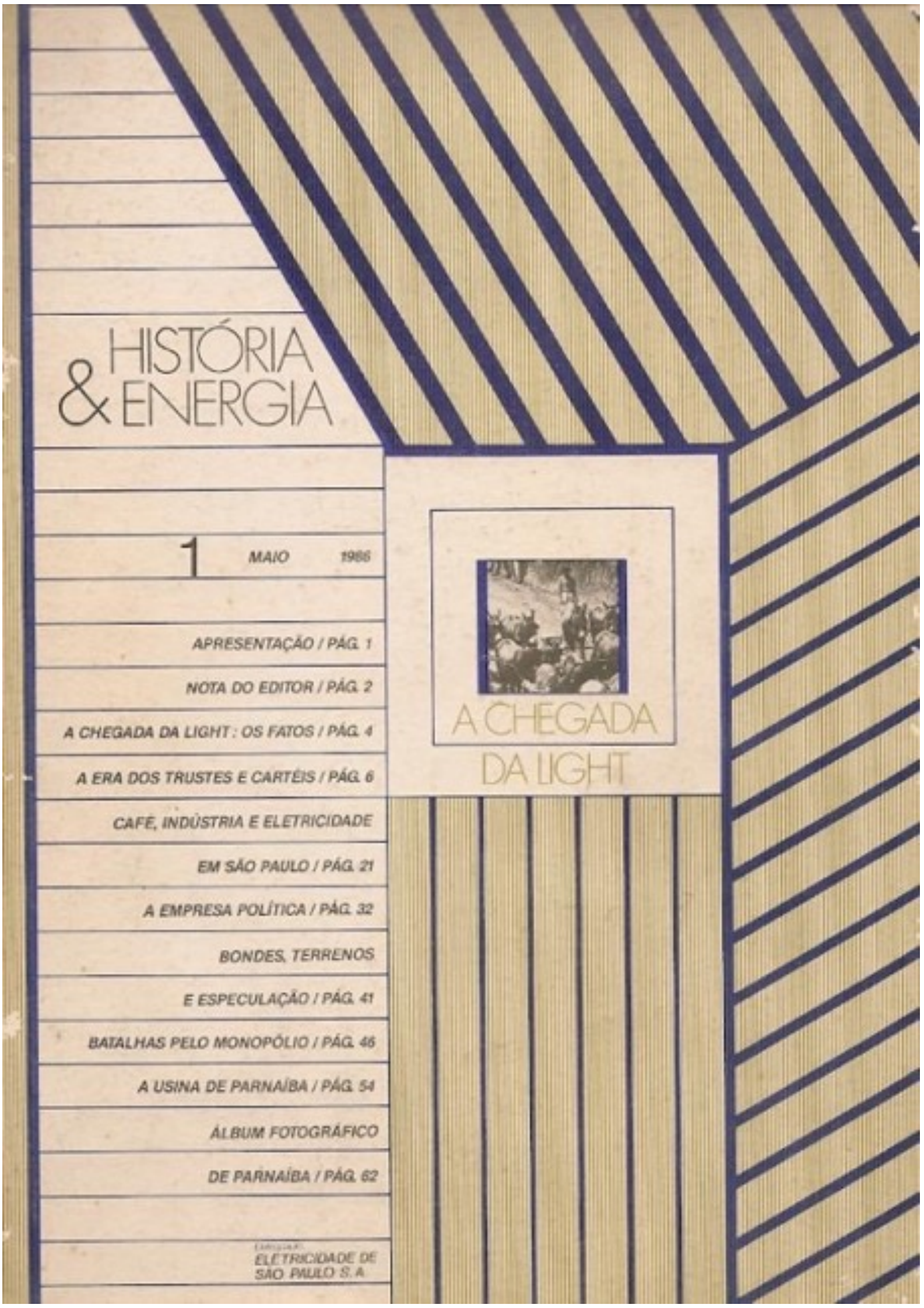

Figura 4. Caderno História \& Energia, A chegada da Light, 1986. 


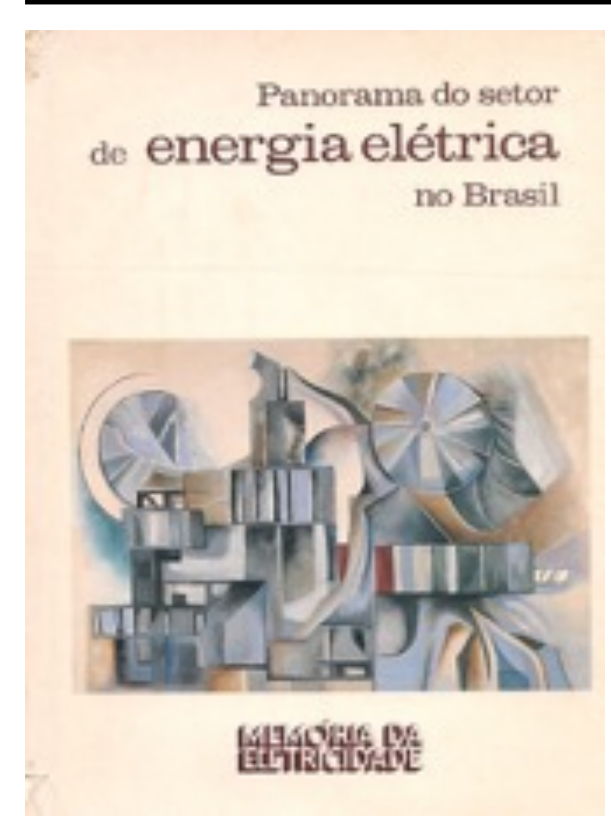

Figura 5. Panorama do setor de energia elétrica no Brasil, 1988.

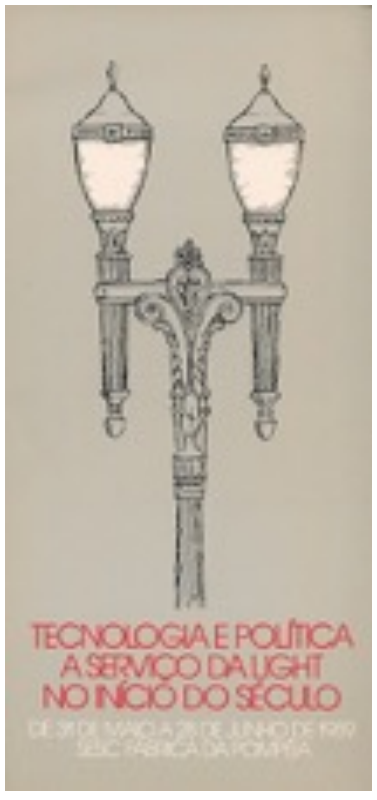

Figura 6. "Folder" da Exposição A Cidade Iluminada, 1989.

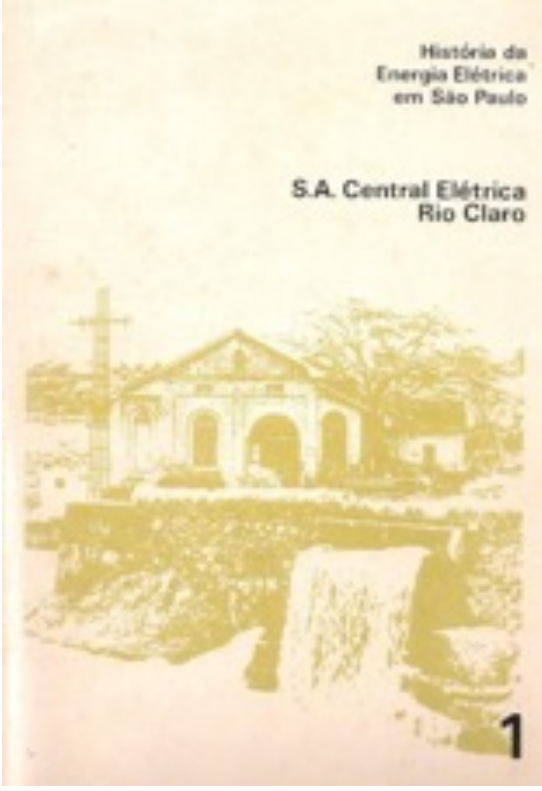

Figura 7. S. A. Central Elétrica Rio Claro, 1986.

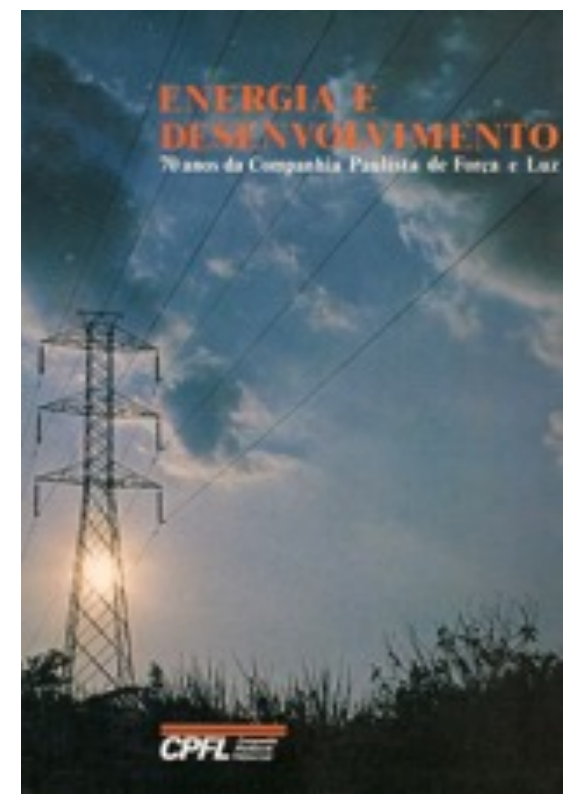

Figura 8. 70 anos da Companhia Paulista de Força e Luz, 1982.

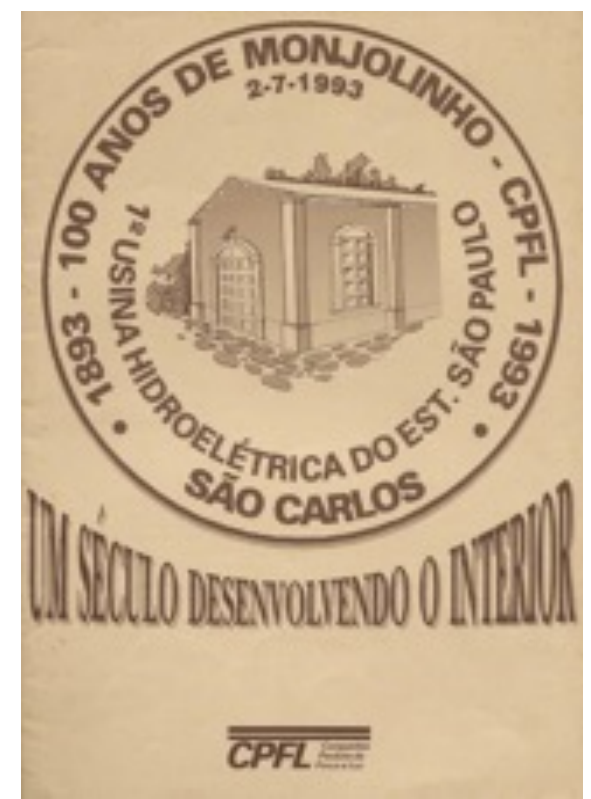

Figura 9. "Folder" de comemoração dos 100 anos da Usina de Monjolinho, 1983.

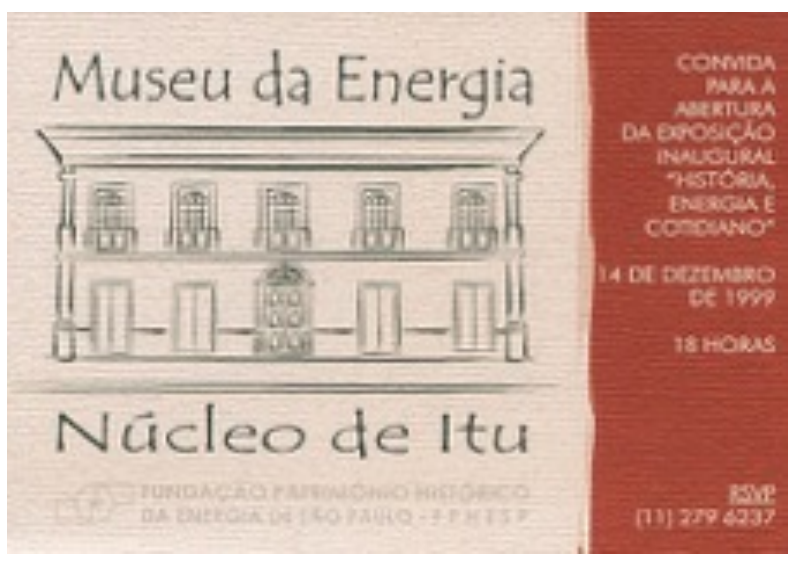

Figura 10. Convite para inauguração do núcleo de Itu do Museu da Energia, 1999. 


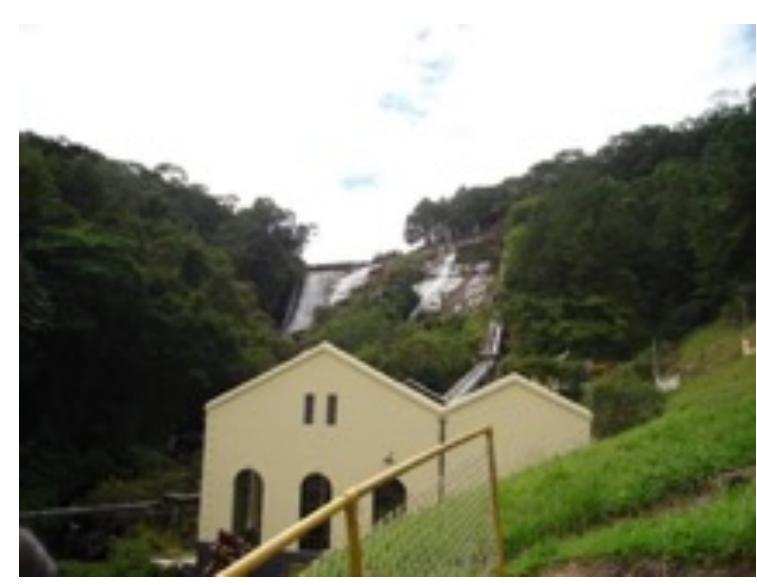

Figura 11. Usina de Salesópolis, geração hidrelétrica e núcleo do Museu da Energia. Foto: Renato Diniz, 2010.

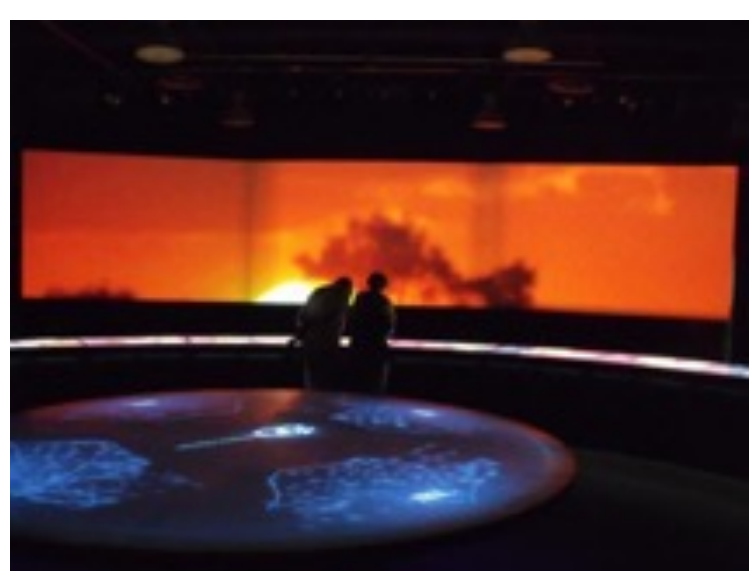

Figura 12. Exposição 100 Anos de História e Energia, Campinas, 2012. Foto Renato Diniz, 2012.

\section{Referências}

BOLETIM Histórico, Cadernos História \& Energia, Revista Memória e Memória Eletropaulo, A História da Light, São Paulo Registros, Exposição Cidade Iluminada, Seminário História \& Energia.

CARR, Edward Hellet. O que é história? Rio de Janeiro: Paz e Terra, 2002.

DINIZ, Renato de Oliveira. Cem Anos de História e Energia. São Paulo: Via das Artes, 2012.

DINIZ, Renato de Oliveira. Funcesp: 45 anos para o futuro, 1969-2014. São Paulo: Perfil Cultural, 2014.

MARANHÃO, Ricardo; MATEOS, Simone Biehler. Cem Anos de História e Energia. São Paulo: Andreato, 2012.

MORTATI, Débora M. de A. N. A implantação da Hidreletricidade e o processo de ocupação do território no interior paulista (1890-1930), 2013. Tese (Doutorado em Engenharia Civil). Campinas: UNICAMP, 2013.

SANTOS FILHO, Gildo Magalhães dos (org.). História e Energia: Memória, Informação e Sociedade. São Paulo: Alameda, 2012.

TOTINI, B.; GAGETE, E. Beth Totini e Élida Gagete. “Memória Empresarial, uma análise da sua evolução”, In: Paulo Nassar. Memória de Empresa: história e comunicação de mãos dadass a construir o futuro das organizações, Rio de Janeiro: Associação Brasileira de Comunicação Empresarial - ABERJE, 2004.

TRÓIA, Rosane; DINIZ, Renato; FERREIRA, Tânia. Museu Descentralizado. Revista Memória, São Paulo, Eletropaulo/Departamento de Patrimônio Histórico, no 9, out./nov./dez. 1990, pp. 51-56.

Web CPFL. http://www.cpfl.com.br

YAGUI, Mirian. Museus e patrimônio industrial: um estudo sobre a musealização do setor elétrico no estado de São Paulo, 2014. Dissertação de Mestrado, Programa de Pós-Graduação Interunidades em Museologia do Museu de Arqueologia e Etnologia da Universidade de São Paulo. 